\title{
Séance du 22 mars 2012
}

Remise de médicaments par le médecin - Les négociations entre la FMH et tarifsuisse au sujet de la propharmacie sont suspendues jusqu'à la réponse du Conseil d'administration de santésuisse. Si aucune solution ne devait être trouvée au niveau de l'organisation faîtière, la FMH continuera à négocier individuellement avec les assureurs afin d'empêcher toute action législative contre la distribution directe de médicaments par le médecin. En agissant ainsi, la FMH souhaite plus particulièrement susciter l'intérêt de ces assureurs pour des projets pilotes.

Swiss Medical Board - L'organisation du Swiss Medical Board (SMB) est active depuis plus d'un an sur le plan national (www.swissmedicalboard.ch). Dans l'intervalle, le SMB a publié deux rapports et accepté la Principauté du Liechtenstein comme nouveau membre. Il a notamment prévu de publier deux brochures à l'intention des patients pour les informer de ses recommandations.

«Démographie Médicale» - La FMH et l'OBSAN vont publier un bulletin commun décrivant la situation actuelle de la profession médicale, le nombre de médecins et leur évolution démographique en Suisse.
IG Rare Diseases - La FMH a adhéré à la Communauté d'intérêt Maladies rares (IG Rare Diseases). Celle-ci entend accompagner activement les travaux de la Confédération en vue d'élaborer une stratégie nationale et devenir l'organe exécutif de l'OFSP. La FMH s'engage à ce que l'IG Rare Diseases se fasse l'écho des préoccupations des patients. On pourra ainsi éviter les conflits d'intérêts potentiels avec l'industrie.

Loi fédérale sur la formation continue - Le Département fédéral de l'économie a mis en consultation la future loi sur la formation continue, qui entend régler les principes, les tâches et les compétences de manière interdisciplinaire. Or son extension aux médecins s'avérerait problématique. La FMH et l'ISFM vont donc élaborer deux prises de position complémentaires à l'intention du DFE.

Abus à caractère sexuel lors de l'activité médicale Le Comité central de la FMH a décidé de soumettre à l'Assemblée des délégués et à la Chambre médicale les propositions du groupe de travail «Abus à caractère sexuel lors de l'activité médicale» visant à modifier le Code de déontologie et à améliorer la collaboration avec les autorités de surveillance.

\section{Nouvel outil pédagogique:} manuel de formation au cabinet médical.

\author{
Ouvrage didactique pour formateurs et \\ assistantes médicales en formation.
}

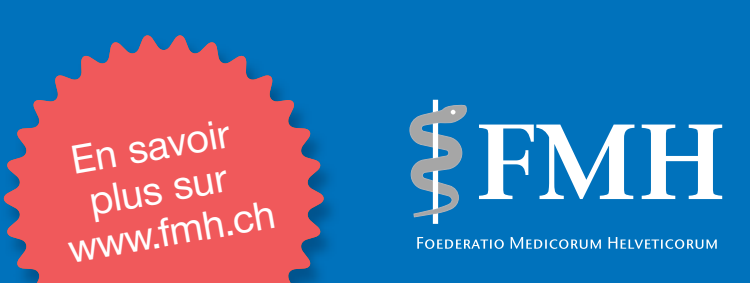

